\title{
Norma, variação e mudança linguísticas nas apresentações das gramáticas de Costa Duarte (1829), Manuel Beserra (1861) e Julio Ribeiro (1881)
}

\author{
Linguistics standard, variation and chance in \\ Costa Duarte's (1829), Manuel Beserra's (1861), and Julio \\ Ribeiro's (1881) grammar presentation
}

Emily Gonçalves de Medeiros Ferreira Universidade Federal da Paraíba, João Pessoa, Paraíba, Brasil

\begin{abstract}
Resumo: Nossa pesquisa ancora-se nos estudos da Historiografia da Linguística (KOERNER, 1996, 2014a, 2014b; SWIGGERS, 2013, 2015, 2019; MURRAY, 1994) e da Sociolinguística Variacionista (HERNANDEZ CAMPOY; ALMEIDA, 2005; CAMACHO, 2013). Neste artigo, nosso objetivo principal foi analisar como gramáticas brasileiras oitocentistas apresentavam os conceitos de norma, variação e mudança linguísticas relacionados à abordagem da língua portuguesa. Tomamos como fontes primárias as gramáticas de Costa Duarte (1829), Manuel Beserra (1861) e Julio Ribeiro (1881), das quais selecionamos para análise as apresentações. Como resultados, destacamos que, a despeito da ausência de um paradigma variacionista estabelecido nas obras brasileiras do século 19 , já encontramos a abordagem da norma tanto numa perspectiva "idealista" quanto "descritivista", a variação diastrática em evidência e a mudança linguística enquanto transformações e aperfeiçoamentos na língua ao longo do tempo.
\end{abstract}

Palavras-chave: Historiografia da Linguística; Sociolinguística Variacionista; Gramáticas Brasileiras oitocentistas

\begin{abstract}
Our research is anchored in the studies of Historiography of Linguistics (KOERNER, 1996, 2014a, 2014b; SWIGGERS, 2013, 2015, 2019; MURRAY, 1994) and Variationist Sociolinguistics (HERNANDEZ CAMPOY; ALMEIDA, 2005; CAMACHO, 2013). In this paper, we main to analyze how 19th century Brazilian grammars presented the concepts of norm, variation and linguistic change related to the approach of the Portuguese language. We take as primary sources the grammars of Costa Duarte (1829), Manuel Beserra (1861) and Julio Ribeiro (1881), from wich we selected the presentations for analysis. As results, we emphasize that, despite the absence of a variationist paradigm established in the 19th century Brazilian grammars, we can see the approach to the norm both in an "idealistic" and "descriptivist" perspective, the diastratic variation in
\end{abstract}

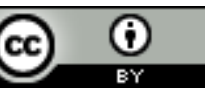


evidence and linguistic change as transformations and improvements in the language over time.

Keywords: Historiography of Linguistics; Variacionist Sociolinguistics; 19th century Brazilian Grammars

\section{Introdução}

A reflexão acerca dos fenômenos linguísticos é uma prática antiga no mundo Ocidental, cujos registros têm como berço o período clássico e alcançam o século 21, a partir de diversas abordagens. Dentre elas, pode-se dizer que a gramática tradicional, uma "teoria das línguas humanas surgida na Antiguidade clássica e que se mantém essencialmente igual até os nossos dias" (BORGES NETO, 2012, p. 88), adquiriu estabilidade tal ao longo do tempo que ultrapassou seu estatuto teórico e passou a ser vista como dogma, questionável apenas dentro de seu próprio sistema, a partir de suas próprias regras.

Com relação às gramáticas brasileiras normativas do português, Vieira (2018) afirma que estas se configuram em um conjunto de princípios e regras fruto da gramática tradicional, ressoando seus pressupostos, técnicas, ideologias e idealizações mediante o que chama paradigma tradicional de gramatização (PTG). No Brasil do século 20, especialmente a partir da década de 1960, a adoção a essa doutrina tradicional e sua respectiva abordagem no ensino-aprendizagem do português brasileiro como língua materna passou a ser alvo de discussões e críticas entre os estudiosos da Linguística, o que desencadeou também uma ampla produção acadêmica sobre o tema.

Nesse contexto, Gueiros (2019, p. 77) observa a ocorrência do que denomina tradição sociodiscursiva (TSD), a qual "se instala na linguística brasileira como uma tradição que estabelece alguns deslocamentos [...] no modo de conceber certos fenômenos de linguagem" e respinga em diversas esferas institucionais - na academia, na escola, nos cursos de formação continuada, em avaliações de larga escala, em livros didáticos. Dessa tradição emergem novas frentes de tratamento à língua que resultam da interlocução entre a Linguística e outras disciplinas das ciências humanas e sociais. Dentre elas, destacamos a Sociolinguística, sobretudo de cunho variacionista, cujos estudos são oriundos do diálogo entre a Linguística, frente aos fenômenos de variação e mudança da língua, e outras ciências sociais, frente aos mais diversos fato(re)s. 
Uma das consequências desses novos olhares sobre o objeto língua foi o surgimento, já nas primeiras décadas já do século 21, das gramáticas dos linguistas brasileiros. Em linhas gerais, essas obras representariam o cenário normativo contemporâneo que, em diálogo com os apanhados das diferentes teorias linguísticas, não se limita ao aparato terminológico e metodológico do PTG. Assim, elas se constituem frente um espírito do tempo em que se propõe o rompimento com a concepção normativa reconhecida pelo dogma tradicional. Mas até que ponto os pressupostos da tradição gramaticográfica brasileira efetivamente divergem das atuais perspectivas sobre o fazer gramatical?

Diante disso, o presente artigo teve como objetivo principal compreender como as apresentações de gramáticas brasileiras oitocentistas abordam norma, variação e mudança linguísticas relacionadas à abordagem da língua portuguesa. Tomamos por fontes primárias obras do século 19 , pois este período foi marcado pelo reconhecimento das especificidades da língua do Brasil, o que sugere haver visibilidade em relação a variações e mudanças na língua portuguesa. Isso se deve, entre outros fatores, ao desligamento político do Brasil em relação à matriz lusitana, no qual se deu o estopim da gramatização nacional. Este trabalho surge a partir de uma dissertação de mestrado em andamento, na qual analisamos 16 gramáticas brasileiras publicadas ao longo do século 19. Dentre elas, selecionamos três com datas de publicação espaçadas, de modo a abrangermos diferentes momentos dos oitocentos: Costa Duarte (1829), Manuel Beserra (1861) e Julio Ribeiro (1881).

Mediante a natureza de nosso objeto de estudo, esta foi uma pesquisa fundamentalmente documental, bibliográfica e interpretativa. Ancoramo-nos em algumas das contribuições da Sociolinguística Variacionista (HERNANDEZ CAMPOY \& ALMEIDA, 2005; CAMACHO, 2013) e da Historiografia da Linguística (KOERNER, 1996, 2014a, 2014b; SWIGGERS, 2013, 2015, 2019; MURRAY, 1994), a partir das quais também elencamos, respectivamente, como categorias de análise: (i) norma, variação e mudança; (ii) retórica de continuidade e retórica de ruptura.

A relevância desse estudo se faz por entendermos que essa temática excede os limites estritamente internos à língua. A norma linguística (e compreendemos os instrumentos gramaticais enquanto seus principais transmissores ao longo da história) serve como ferramenta às funções práticas e sociais do cotidiano da comunidade de fala 
à qual pertence, aqui compreendida a nação brasileira. Por ela se estabelecem, a partir do simbólico, relações identitárias entre os indivíduos, concedendo-lhes identificação e sentimento de pertença ao mesmo povo, enraizando sua cultura e valores (FIORIN, 2008). Desse modo, a normatização da língua reflete questões políticas, sociais e educacionais, as quais modificam diferentes espaços da sociedade, e o resgate ao seu fundamento epistêmico à luz dos princípios da Sociolinguística nos direciona a uma postura mais crítica em relação à cultura gramatical e escrita da contemporaneidade.

\section{Aspectos teórico-metodológicos}

O que se tem compreendido por Historiografia da Linguística (HL), nos termos de Koerner (1996, 2014a, 2014b) e Swiggers (2013, 2015, 2019), corresponde a um empreendimento metodológica e epistemologicamente consciente de se registrar a história dos estudos sobre a linguagem. Enquanto tal, tem como objetivo descrever, compreender e propor justificativas para a emergência, a consolidação, a transmissão e mesmo o esquecimento das teorias e crenças sobre língua e linguagem através dos tempos.

No trabalho com as fontes historiográficas, Koerner (1996) indica a adoção de três princípios de análise: (i) o princípio de contextualização; (ii) o princípio de imanência; e (iii) o princípio de adequação. Em nossa pesquisa, o segundo princípio se fez nuclear à análise, que se deu essencialmente em relação à imanência das obras selecionadas para estudo. Entretanto, também partimos do primeiro, ao compreendermos os aspectos da atmosfera intelectual oitocentista desvelado pelas gramáticas em sua argumentação, e do terceiro, à medida que estabelecemos paralelos em direção aos conceitos da Sociolinguística Variacionista.

Outro autor de reconhecida importância para os estudos da HL foi o sociólogo e antropólogo Murray (1994) que, entre outras contribuições, apresentou um modelo representativo dos movimentos realizados nos estudos sobre a linguagem. O modelo de conflito proposto pelo autor compreende que os estudos sobre a linguagem se constituem em meio a paradigmas coocorrentes, não havendo teorias realmente revolucionárias. Assim, o autor identifica uma retórica de continuidade, que pode ser reconhecida no discurso que se assume em dívida para com determinada tradição de pesquisa, e uma 
retórica de ruptura, que diz respeito à adoção de um posicionamento que, em graus variáveis, desconsidera ou efetivamente se opõe ao trabalho de seus predecessores. Neste cenário, um dos focos de nosso estudo foi a autopercepção que os gramáticos brasileiros oitocentistas têm sobre si mesmos, sobre suas respectivas obras e sobre a abordagem normativa em que as baseiam.

Em se tratando dos conceitos de norma, variação e mudança na língua, uma das principais correntes que abordam esses conceitos e se faz fundamental ao nosso estudo é a Sociolinguística Variacionista (SV), que apresenta o binômio variação-e-mudança como uma propriedade constitutiva da linguagem (CAMACHO, 2013). Os estudos sobre a linguagem têm se desenvolvido, ao longo do tempo, entre duas extremidades: uma orientação normativa, que, em geral, conduz à compreensão equivocada de que apenas a variedade prestigiada é sistemática e regular; e uma orientação descritiva, em que se observam a estrutura, as variantes e as variáveis das línguas em funcionamento. Enquanto no primeiro cenário quaisquer divergências em relação à norma privilegiada consistem em formas corrompidas que precisam ser corrigidas, o segundo abre caminhos à ressignificação das variedades estigmatizadas, agora percebidas enquanto facetas da língua que se organizam de modo diferente da forma prestigiada.

Hernandez Campoy \& Almeida (2005) afirmam que a variação linguística se expressa em quatro tipos: (i) o diacrônico, que comporta as variações que, persistentes ao longo do tempo, perdem o status de exceções na língua e se estabelecem como parte de sua estrutura comum; (ii) o diatópico, que abarca as diferenças linguísticas decorrentes da distinção geográfica donde se originam os falantes; (iii) o diastrático, que compreende os estratos sociais em que os falantes estão inseridos; e (iv) o diafásico, que abarca fatores relacionados ao contexto situacional da comunicação.

$\mathrm{Na}$ análise das gramáticas oitocentistas, observamos o modo como as obras concebem gramática e língua, bem como suas demandas e seus propósitos sociais, a fim de vislumbrarmos suas perspectivas acerca do que hoje compreendemos por norma, variação e mudança. Assim, analisamos, nas apresentações das três obras selecionadas, as percepções dos autores em relação: (a) às demandas e aos propósitos sociais das obras; (b) ao conceito de gramática; (c) às concepções de língua(gem) e sua relação com a abordagem (normativa, descritiva) da obra; (d) a presença/ausência de variação e mudança e suas respectivas implicações. 


\section{Analisando as obras}

Nesta seção, apresentamos os resultados e as discussões de nossa análise a partir da imanência das apresentações das três gramáticas, seguindo a ordem cronológica das publicações. $^{1}$

\subsection{Antonio da Costa Duarte (1829)}

O Compendio da Grammatica Portuguesa, de Costa Duarte, foi publicado na província do Maranhão, em 1829, já no Brasil Império, com o objetivo de ser instrumento de estudo da língua portuguesa nas Escolas de Primeiras Letras. Para isso, o autor oferece e dedica sua obra ao " $\mathrm{Ilm}^{\circ}$. e Exm Sr. Candido Joze de Araujo Vianna, Deputado nas Cortes Legislativas, Cavaleiro da Ordem de Cristo, e Desembargador da Relação de Pernambuco", solicitando sua leitura e correção para que seja de interesse à instrução da mocidade. Esta obra se coloca em continuidade à tradição gramatical desde o seu subtítulo: "ordenado Segundo a Doutrina dos Melhores Gramáticos", dispensando qualquer contraposição em relação à tradição gramatical vigente.

$\mathrm{Na}$ Introdução, onde as intenções da obra são de fato apresentadas, o autor afirma haver uma íntima conexão e correspondência entre as "operações do espírito" humano, isto é, a formação do pensamento, e a linguagem articulada, a partir da qual se exprimem os pensamentos. O "procedimento" desse espírito é caracterizado pelo autor como uniforme, único e imutável, e essas mesmas características são atribuídas à chamada Gramática Universal. Nesse esteio, Costa Duarte (1829, n.p.) define a Gramática Universal como a "[a]rte, que analisando o pensamento, ensina com que espécie de palavras se devem exprimir as ideias e as relações, de que ele pôde constar".

Por imutável, o autor nos diz que as características dessa gramática são comuns aos falantes de todas as nações. Cada nação, porém, as materializa em diferentes sons, que formam as diferentes línguas e, como consequência, geram a necessidade de se estabelecer Gramáticas Particulares para sua compreensão. Assim, o autor parte do

\footnotetext{
${ }^{1}$ Os trechos transcritos foram adequados à ortografia do século 21, a fim de tornar a leitura e a compreensão dos excertos mais fluida. Os conteúdos e a pontuação de cada fragmento, contudo, foram preservados fiéis aos originais.
} 
pressuposto de que todas as línguas têm princípios comuns invariáveis, cujo estudo deve ser realizado anteriormente à sua aplicação aos usos das línguas particulares. Para Costa Duarte (1829, n.p.), então, um instrumento gramatical

[...] deve tratar da parte mecânica das Línguas, observando os sons articulados elementares e fundamentais da Linguagem; as sílabas que resultam da sua diferente combinação; o tom e quantidade da voz na pronunciação dos mesmos sons no corpo dos vocábulos; e finalmente os caracteres literais, adotados pelo uso, para representarem e fixarem estes mesmos sons e vocábulos na escritura.

Apesar do aparente caráter descritivo que esse fragmento da obra denota, ela tem como princípio uma finalidade essencialmente normativa, pois uma gramática portuguesa seria a "arte que ensina a falar, ler, e escrever sem erros a Língua Portuguesa" (COSTA DUARTE, 1829, p. 9). Nesse esteio, podemos inferir uma visão de língua idealizada e de abordagem integralmente normativa, que de fato se filia ao que Vieira $(2015 ; 2018)$ caracterizou como PTG. Assim, não há espaço para variação e mudança entre os pressupostos de análise linguística apresentados na Introducção da obra (ainda que esta venha a lume na mesma década em que o Brasil proclama sua independência em relação à colônia portuguesa), uma vez que Costa Duarte (1829) assume a língua portuguesa por ele gramatizada enquanto uma unidade uniforme e prescritível.

\subsection{Manuel Beserra (1861)}

Manuel Beserra, bacharel em Ciências Sociais e Jurídicas, procurador fiscal e dos feitos da fazenda, lente substituto de Geometria e membro do Conselho Diretor da Instrução Pública no Lyceu do Ceará, publicou o Compendio de Grammatica Philosophica em solo cearense, no ano de 1861, para uso do lyceu provincial. No Prefácio à obra, o autor a apresenta como um trabalho que, apesar de imperfeito, é fruto de estudos e meditação atentos sobre as obras gramaticais então mais utilizadas no ensino público. Em suas observações, Beserra (1861, n.p., grifos nossos) afirma:

[...] parece-me incontestável que, quanto se há escrito sobre Gramática em nossa língua, não passa de modificações mais ou menos bem assombradas $e$ ilusórias de dois grandes erros, que por sem crítica e sem reflexão têm passado desapercebidos até hoje. Falo da filosofia sensualista, que ocupou o vasto império do mundo, e da imitação servil da língua latina, que tem dominado a nossa. 
Diante desse cenário, Beserra (1861) se coloca num embate em relação a essas obras, concebendo sua gramática em um caráter de novidade a partir de uma retórica de ruptura com a "filosofia sensualista" e a "imitação servil da língua latina". Do ponto de vista que o autor nos apresenta, esses dois fatores tradicionalmente se utilizavam na abordagem gramatical da língua vernacular, sendo a língua portuguesa subserviente à latina e à filosofia clássica. Seu papel enquanto revolucionário se dá justamente na emancipação do português, que portanto deveria ser analisado de acordo com sua própria estrutura. Conforme ele resume:

\begin{abstract}
Pelo que escrevi, se deixa ao menos entrever, creio eu, que procurei libertar a nossa língua dessa servidão que nos legaram os antigos clássicos, os quais, como disse o grande Frei Francisco de S. Luis no seu Glossário, por falta de estudo filosófico da língua, caíram em muitos defeitos no que respeita a organização da frase e discurso, que hoje seriam erros graves, e talvez indesculpáveis (BESERRA, 1961, n.p., grifos nossos).
\end{abstract}

Os trechos em destaque fazem sobressair, novamente, a retórica revolucionária do autor. Nestes, percebemos que Beserra não apenas se propõe opositor da tradição clássica, mas também a critica severamente, ao afirmar que a falta de estudo dos autores fez com que erros de abordagem da língua portuguesa fossem perpetuados. Noutros termos, o autor quer dizer que a sua gramática desvela tudo aquilo que outros, inadvertidos pela falta de um conhecimento adequado, falharam em retratar e, portanto, sua obra se torna uma autoridade superior na exposição dos fatos da língua.

Compreendemos, através da leitura integral do Prefácio, que a obra de Beserra (1861) veio a lume não apenas para apontar os erros dessa tradição, mas também para trazer à abordagem gramatical da língua uma alternativa em que se aborda suas características intrínsecas, sem a influência de um panorama latinizado. Contudo, isso não significa que Beserra (1861) desvincule de todo o português do latim. Ao contrário, na perspectiva apresentada pelo autor, a grande problemática à qual ele se contrapõe se dá em, por ser a língua portuguesa oriunda da latina, os gramáticos desejarem imprimirlhe mesma estrutura, mesmas regras, mesmo método de análise.

A crítica do autor se dirige ao fato de ser o latim uma língua morta, e defende ele que, como tal, não há direito em se fazer com que a língua portuguesa, língua viva e "que no correr dos séculos se tem vindo transformando e aperfeiçoando" (BESERRA, 1861, n.p.), se submeta às suas leis. Nesse sentido, identificamos, no discurso revolucionário do 
autor, uma concepção de língua enquanto mutável, passível de sofrer modificações através do tempo. Por sua vez, essa língua é concebida enquanto uma unidade, e o fenômeno da variação sincrônica não é mencionado pelo autor na apresentação da obra.

Nessa empreitada, Beserra (1861, p. 1) concebe a gramática como "arte que ensina as leis da expressão do pensamento por palavras”. Esta se divide, à semelhança do que vimos em Costa Duarte (1829), em Gramática Geral ou Universal, que ensina o fundamento essencial da linguagem comum a todas as línguas, e Gramática Particular, que ensina a aplicação de tal fundamento às particularidades de cada língua. $\mathrm{Na}$ apresentação da obra, portanto, identificamos o objetivo de retratar as particularidades do português sem que haja subserviência à estrutura da língua latina.

\subsection{Julio Ribeiro (1881)}

A Grammatica Portugueza, de Julio Ribeiro, foi publicada em 1881. Elia (1975) aponta esta obra como aquela que instituiu novas teorias no fazer gramatical brasileiro e, com isso inaugurou o seu período dito científico. De fato, os pressupostos com os quais nos deparamos, na apresentação da gramática, nitidamente se distanciam daquilo que pudemos observar nas duas anteriores - cuja orientação fora, em geral, fundamentada em preceitos de base filosófica.

Ainda que a obra em questão seja marco nesse processo de ruptura em relação ao chamado período filosófico, não identificamos em sua apresentação uma retórica de ruptura. Com efeito, a veia científica que encontramos em Julio Ribeiro (1881) é anunciada apenas a partir dos pressupostos de sua gramática, expostos sem um direcionamento em relação a tradições ou autores que precederam a sua publicação. A obra parece aludir, na verdade, à sua própria projeção nos estudos gramaticográficos do autor, conforme cumpre-nos notar no seguinte excerto:

Peço à crítica ilustrada e honesta o que ela me não pode recusar - toda $a$ severidade para com esta Gramática.

Não é um orgulho tolo que me leva a fazer tal pedido: é o desejo de melhorar o meu trabalho em bem dos que estudam Português.

Dos diretores da imprensa espero espero uma fineza - que me sejam enviados todos os exemplares das suas folhas, em que saiam notícias e apreciações desta obra (RIBEIRO, 1881, n.p., grifos nossos). 
As duas solicitações em destaque dialogam entre si reafirmando um mesmo propósito: o de conceder ao autor a percepção de como sua gramática seria recebida por seus leitores e críticos e seu consecutivo aperfeiçoamento - conforme ele mesmo estabelece, ainda neste fragmento, ao afirmar ter o desejo de melhorar o seu trabalho. Desse modo, o discurso de Ribeiro deixa claro o seu intuito de a longo prazo desenvolver e aprimorar a sua abordagem gramatical da língua portuguesa, "em bem dos que estudam Português".

Ribeiro (1881, p. 1) abre a sua seção introdutória ancorado em William Dwight Witney $^{2}$, no que conceitua Gramática como "a exposição metódica dos fatos da linguagem". A partir dessa definição, o autor acrescenta que o propósito da gramática não é estabelecer leis e regras da linguagem, mas sim trazer a lume os fatos a ela circunscritos. Desse modo, ele afirma que a fala e a escrita corretas são adquiridas no cotidiano dos sujeitos em suas interações sociais, "[o]uvindo bons oradores, conversando com pessoas instruídas, lendo artigos e livros bem escritos" (RIBEIRO, 1881, p. 1). As regras do bom uso da linguagem, em tal conjuntura, servem como facilitadoras do aprendizado e como "único meio que têm de corrigir-se os que na puerícia aprenderam mal a sua língua" (RIBEIRO, 1881, p. 1).

Parece claro, em tais passagens, que o autor tenha assumido um compromisso de cunho descritivo com o seu objeto de estudo. Contudo, tal objeto não passa incólume às noções normativas de acerto e de erro, haja vista que o autor se refere a um mal aprendizado da língua e à tomada de pessoas e textos cultos como exemplos de bom uso. Compreendemos, então, que o autor identifica a coocorrência de diferentes formas dentro de uma mesma língua - que particularmente nos remete à perspectiva estratificada da variação -, mas também aponta à eleição de uma única forma como aquela que representa o seu desempenho ideal.

Ribeiro (1881) afirma, à semelhança das obras anteriormente analisadas, que a gramática se divide em Gramática Geral, que corresponde à exposição metódica dos fatos da linguagem em geral, e Gramática Particular, que diz respeito à exposição metódica dos fatos de uma língua determinada. A Gramática Portuguesa, portanto, é a exposição sistemática dos fatos da língua portuguesa, e é a este objeto que o autor se dedica em sua

\footnotetext{
${ }^{2}$ WITNEY, W. D. Essentials of English Grammar, London, 1877, p. 4-5. Cf. RIBEIRO, 1881.
} 
obra. Cumpre-nos notar, porém, um aspecto que a diferencia das demais: enquanto Costa Duarte (1829) e Beserra (1861) abordam as gramáticas geral (ou universal) e particular por uma perspectiva “essencialista”, isto é, referindo-se aos próprios métodos, princípios e fundamentos intrínsecos à linguagem na expressão do pensamento, Ribeiro (1881) as concebe a partir de uma perspectiva "sistemática", referindo-se à gramática enquanto o próprio método de descrição da língua. Em outras palavras, para os dois primeiros autores, a gramática corresponderia à própria língua; já para Julio Ribeiro, ela corresponderia à estratégia de abordagem da língua.

O autor apresenta, ainda, uma série de razões ante as quais o estudo da gramática se faz útil - e aqui compreendemos, também, a sua própria obra.

Em primeiro lugar, ele cita que o aprendizado da língua se faz, antes de tudo, na aquisição da fala, passando de um estágio de compreensão a, posteriormente, outro de pronúncia e coordenação da estrutura da língua, os quais nos permitem (respectivamente) assimilar e exprimir impressões e pensamentos. Só depois é que nos inserimos no contexto da cultura escrita, quando então será “dever nosso usar a linguagem, não só com correção, mas também de modo que agrade aos outros, que sobre eles exerça influência" (RIBEIRO, 1881, p. 1). Desse modo, subentende-se a utilidade da gramática para o domínio mais proveitoso da escrita, que nos favoreça a retórica e a argumentação.

Outra razão apresentada pelo autor se dá no aprendizado de línguas estrangeiras, "que servem aos mesmos fins a que serve a nossa, mas de modo diverso" (RIBEIRO, 1881, p. 2). Para tal propósito, o estudo da língua vernacular se faz necessário para que, comparando-a às demais, possamos compreendê-las com maior perspicuidade acerca de sua estrutura, quanto ao que é e ao como veio a ser o que é.

Uma terceira e última razão é apresentada por Ribeiro (1881, p. 2): “[n]ão nos basta usar da linguagem; é mister saber o que constitui a linguagem, e o que nos importa ela”. Ele afirma que o estudo da linguagem faz transparecer muito da natureza e da história do ser humano. Pois, sendo a linguagem o instrumento e o meio principal das operações da mente, "não podemos estudar essas operações e a sua natureza sem um conhecimento cabal da linguagem" (RIBEIRO, 1881, p. 2). Nesse esteio, Julio Ribeiro (1881) defende, na apresentação de sua obra, a expansão progressiva e constante da compreensão acerca da linguagem, mesmo da língua materna, como uma característica 
dos homens mais inteligentes e doutos - o que entrementes deixa a entender que aqueles que desejam ser inteligentes e doutos devem sempre buscar o mesmo.

\subsection{Concepções em sintese}

O Quadro 1 reúne sistematicamente os principais achados de nosso levantamento:

\begin{tabular}{|c|c|c|c|c|c|c|c|}
\hline OBRA & RETÓRICA & $\begin{array}{l}\text { DEMANDAS E } \\
\text { PROPÓSITOS }\end{array}$ & GRAMÁTICA & LÍNGUA(GEM) & ABORDAGEM & VARIAÇÃO & MUDANÇA \\
\hline $\begin{array}{l}\text { Costa } \\
\text { Duarte } \\
(1829)\end{array}$ & Continuísta & $\begin{array}{l}\text { Para o ensino da } \\
\text { gramática de } \\
\text { língua } \\
\text { portuguesa em } \\
\text { Escolas de } \\
\text { Primeiras Letras } \\
\text { da província do } \\
\text { Maranhão. } \\
\end{array}$ & $\begin{array}{l}\text { Arte de falar, } \\
\text { ler e escrever } \\
\text { corretamente. }\end{array}$ & $\begin{array}{l}\text { Visão de língua } \\
\text { idealizada. }\end{array}$ & $\begin{array}{c}\text { Normativa } \\
\text { (visando a fala, } \\
\text { a leitura e a } \\
\text { escrita sem } \\
\text { erros). }\end{array}$ & $\begin{array}{c}\text { Não } \\
\text { mencionada } \\
\text { na } \\
\text { apresentação } \\
\text { da obra. }\end{array}$ & $\begin{array}{c}\text { Não mencionada } \\
\text { na apresentação } \\
\text { da obra. }\end{array}$ \\
\hline $\begin{array}{c}\text { Manuel } \\
\text { Beserra } \\
(1861)\end{array}$ & Revolucionária & $\begin{array}{c}\text { Abordagem } \\
\text { gramaticográfica } \\
\text { da língua } \\
\text { portuguesa de } \\
\text { modo } \\
\text { independente da } \\
\text { tradição } \\
\text { latinizada, para } \\
\text { uso do lyceu } \\
\text { provincial. }\end{array}$ & $\begin{array}{l}\text { Arte que ensina } \\
\text { as leis da } \\
\text { expressão do } \\
\text { pensamento por } \\
\text { palavras. }\end{array}$ & $\begin{array}{l}\text { Visão de língua } \\
\text { enquanto } \\
\text { unidade (a língua } \\
\text { portuguesa } \\
\text { contraposta à } \\
\text { língua latina). }\end{array}$ & $\begin{array}{l}\text { Normativa e } \\
\text { descritiva } \\
\text { (características } \\
\text { próprias da } \\
\text { língua } \\
\text { portuguesa). }\end{array}$ & $\begin{array}{c}\text { Não } \\
\text { mencionada } \\
\text { na } \\
\text { apresentação } \\
\text { da obra. }\end{array}$ & $\begin{array}{c}\text { Transformações } \\
\text { e } \\
\text { aperfeiçoamentos } \\
\text { na língua ao } \\
\text { longo do tempo. }\end{array}$ \\
\hline $\begin{array}{l}\text { Julio } \\
\text { Ribeiro } \\
\text { (1881) }\end{array}$ & Indeterminada & $\begin{array}{l}\text { Ensino da } \\
\text { gramática de } \\
\text { língua } \\
\text { portuguesa para } \\
\text { domínio da } \\
\text { escrita } \\
\text { vernarcular, } \\
\text { aprendizado de } \\
\text { línguas } \\
\text { estrangeiras e } \\
\text { estudo da } \\
\text { linguagem. }\end{array}$ & $\begin{array}{c}\text { Exposição } \\
\text { metódica dos } \\
\text { fatos da língua. }\end{array}$ & $\begin{array}{l}\text { Visão de língua } \\
\text { enquanto } \\
\text { passível a formas } \\
\text { coocorrentes. }\end{array}$ & $\begin{array}{c}\text { Descritivo- } \\
\text { normativa } \\
\text { (variedade culta } \\
\text { como } \\
\text { desempenho } \\
\text { linguístico } \\
\text { ideal). }\end{array}$ & $\begin{array}{l}\text { Diferentes } \\
\text { camadas } \\
\text { sociais } \\
\text { (diastrática). }\end{array}$ & $\begin{array}{c}\text { Não mencionada } \\
\text { na apresentação } \\
\text { da obra. }\end{array}$ \\
\hline
\end{tabular}

Fonte: elaborado pela autora.

As apresentações analisadas nos forneceram um breve panorama dos pressupostos oitocentistas de gramatização em diferentes momentos históricos. A primeira gramática foi publicada na mesma década do processo de independência do Brasil; a segunda veio a lume já na segunda metade do século, sob uma orientação explicitamente filosófica; e a terceira, de 1881, inaugurou o período científico dos estudos linguísticos brasileiros. 
No que se refere à retórica dos autores, as apresentações das obras nos forneceram três tipos de posturas distintos: ruptura, no caso de Beserra (1861); continuidade, em Costa Duarte (1829); e indeterminada, em Julio Ribeiro (1881). À leitura desses dados se faz de suma importância a observação da terceira coluna do Quadro 1, a saber, das demandas e dos propósitos que fundamentam sua elaboração. As três gramáticas assumem um compromisso com o ensino da língua portuguesa, embora apenas Costa Duarte e Manuel Beserra direcionem seus escritos ao uso institucional.

Diante disso, constatamos que, apesar do interesse comum em lidar com questões do ensino e da aprendizagem de língua(s), não há uma uniformidade no tipo de domínio em cujo esteio os autores baseiam suas abordagens, e nos deparamos, no âmbito discursivo dessas apresentações, tanto com movimentos de ruptura com o que se considerava tradicional na produção gramatical quanto de continuidade e apropriação dos conhecimentos já adotados socialmente. Nesse ponto, cumpre-nos destacar a gramática de Julio Ribeiro como uma que, apesar de romper com a orientação filosófica então vigente, não deixa marcas discursivas de natureza revolucionária ou continuísta, cumprindo apenas à própria exposição marcar o seu lugar frente ao modo de se fazer gramática oitocentista.

Em se tratando do conceito de gramática, Costa Duarte (1829) e Beserra (1861) a associam a "arte" e à correção, enquanto Ribeiro (1881) a concebe como "exposição metódica". Noutros termos, o que os autores entendem por gramática dá a entender, nos dois primeiros casos, um tratamento da língua estreitamente normativo, e no último, a partir de um caráter descritivo. Contudo, o que se percebe a partir das demais categorias de análise é que essa classificação não é demarcada de modo rigoroso.

Encontramos, por exemplo, na apresentação da obra de Beserra (1861), uma perspectiva de língua enquanto passível de variações e mudanças. Assim, apesar de haver uma visão de língua enquanto unidade (ao contrapor o português ao latim) e uma perspectiva gramatical de cunho normativo, a obra se tornaria descritiva ao expor regras do português de modo independente da tradição latinizada.

Julio Ribeiro (1881), por sua vez, ao tomar por princípio uma abordagem descritiva da língua, então tomada como sujeita a formas coocorrentes, não deixa de lado o componente normativo, pois toma a variedade culta do português como execução ideal da língua. Nesse sentido, encontramos na apresentação dessa gramática vestígios de uma 
percepção de variação na língua, ainda que este não seja um aspecto sobre o qual o autor se debruce nesta parte da obra.

Quanto à gramática de Costa Duarte (1829), a única dentre as obras selecionadas cuja apresentação é marcada por uma retórica continuísta à tradição clássica, não identificamos menções (pontual ou transversalmente) a variações ou mudanças. Com efeito, sua apresentação é marcada por uma abordagem necessariamente normativa, voltada à correção na fala, na leitura e na escrita que se alicerça em uma visão de língua idealizada.

\section{Considerações finais}

Com base nos resultados das análises das apresentações de Costa Duarte (1829), Manuel Beserra (1861) e Julio Ribeiro (1881), constatamos que, apesar dos conceitos de norma, variação e mudança não se encontrarem operacionalmente definidos em cada obra, algumas de suas características estão fundidas às perspectivas de gramática e língua dos autores, bem como às demandas e propósitos com os quais estes se comprometem.

A respeito da norma, os excertos analisados evidenciaram sua presença marcada enquanto "correção da língua" como pressuposto trabalhado nas apresentações das obras. Contudo, distinguimos uma orientação normativa "idealista" e uma orientação normativa de base "descritiva". No primeiro caso, que remete especialmente a Costa Duarte (1829), o autor não explicita nenhum tipo de compromisso com as formas e usos da língua, e se refere especificamente à exposição de regras para o uso correto da língua. No segundo caso, que então se refere a Beserra (1861) e Ribeiro (1881), nos deparamos com uma abordagem que visa o ensino de regras ancorado em algum recorte particular da língua portuguesa.

Dentre os tipos de variação linguística que nos são atualmente apresentados pela $\mathrm{SV}$, identificamos nas apresentações das obras fundamentalmente a presença da variação diastrática, que aponta à coocorrência de formas oriundas de diferentes estratos sociais dentro de uma mesma comunidade de fala. Outros tipos de variação não parecem figurar, a princípio, como parte das premissas das obras.

Quanto à mudança na língua, esta se fez presente especialmente na apresentação de Beserra (1881), que assimila transformações e aperfeiçoamentos ao longo do tempo. 
Contudo, salientamos que a ausência dessa percepção nas demais introduções poderia indicar a ausência de um paradigma oitocentista nesse sentido, ainda que seja perpassado pelo PTG.

Por fim, compreendemos que essa análise nos fornece um panorama no qual figuram diferentes posturas e discussões em relação ao fazer gramatical nos oitocentos, entre as quais respingam alguns dos aspectos adotados na contemporaneidade. Por outro lado, há de se considerar que a análise dessas apresentações não necessariamente assevera que a abordagem dos fenômenos linguísticos das obras se limite aos pressupostos ali expostos. Em outras palavras, o tratamento gramatical dos aspectos fonéticos, morfológicos e sintáticos das obras pode apresentar dados significativos das percepções normativas e de variação e mudança linguística de seus autores que porventura não constem nas seções iniciais das obras, o que exige uma leitura integral das obras.

\section{Referências}

BESERRA, M. S. S. Compendio de Grammatica Philosophica. Ceará: Typographia Social, 1861.

BORGES NETO, J. Gramática tradicional e linguística contemporânea: continuidade ou ruptura. Todas as Letras, v. 14, n. 1, 2012.

CAMACHO, R. G. Da linguística formal à linguística social. São Paulo: Parábola, 2013.

COSTA DUARTE, A. Compendio da Grammatica Portugueza para uso das

Escolas de Primeiras Letras. Maranhão: Typographia Nacional, 1829.

ELIA, S. Os estudos Filológicos no Brasil. In: ELIA, S. Ensaios de Filologia e Linguística. 2. ed. Rio de Janeiro: Grifo, 1975. p. 117-176.

FIORIN, J. L. Língua portuguesa, identidade nacional e lusofonia. Confluência, Rio de Janeiro, n. 33/34, 2 o sem. 2007 / 1o sem. 2008, p. 53-68.

GUEIROS, L. Da emergência à consolidação da tradição sociodiscursiva na pesquisa linguística brasileira e suas implicações para a reflexão sobre ensino de língua portuguesa. Tese (Doutorado em Letras) - Programa de Pós-Graduação em Letras, Universidade Federal de Pernambuco, Recife, 2019.

HERNÁNDEZ CAMPOY, J. M.; ALMEIDA, M. Metodología de la Investigación Sociolingüística. Granada: Comares, 2005. 
KOERNER, E. F. K. A importância da historiografia linguística e o lugar da história nas ciências da linguagem. In: KOERNER. E. F. K. Quatro décadas de historiografia linguística: estudos selecionados. Trás-os-Montes e Alto Douro: Centro de Estudos em Letras, Universidade de Trás-os-Montes e Alto Douro, 2014a. p. 9-15.

KOERNER, E. F. K. Questões que persistem em historiografia linguística. Revista da ANPOLL, n. 2, p. 45-70, 1996.

KOERNER. E. F. K. Historiografia Linguística. In: KOERNER. E. F. K. Quatro décadas de historiografia linguística: estudos selecionados. Trás-os-Montes e Alto Douro: Centro de Estudos em Letras, Universidade de Trás-os-Montes e Alto Douro, 2014b. p. 17-28.

MURRAY, S. O. Theory Groups and the Study of Language in North America: a Social History. Amsterdã: John Benjamins, 1994.

RIBEIRO, J. Grammatica Portugueza. São Paulo: Typographia de Jorge Seckler, 1881.

SWIGGERS, P. A historiografia da linguística: objeto, objetivos, organização.

Confluência, Rio de Janeiro, n. 44-45, p. 39-59, 2013.

SWIGGERS, P. Directions for linguistic historiography. Cadernos de Historiografia Linguística do CEDOCH: VII MiniEnapol de Historiografia Linguística (2013). São Paulo, v. 1, p. 8-17, 2015.

SWIGGERS, P. Historiografia da Linguística: princípios, perspectivas, problemas. In: BATISTA, R. de O. Historiografia da Linguística. São Paulo: Contexto, 2019. p. 4580 .

VIEIRA, F. E. A gramática tradicional: história crítica. São Paulo: Parábola Editorial, 2018.

VIEIRA, F. E. Gramáticas Brasileiras Contemporâneas do Português: linhas de continuidade e movimentos de ruptura com o paradigma tradicional de gramatização. Tese (Doutorado em Linguística) - Programa de Pós-Graduação em Letras, Universidade Federal de Pernambuco, Recife, 2015.

Recebido em: 21 de outubro de 2020 Aceito em: 5 de abril de 2021

Publicado em maio de 2021

Emily Gonçalves de Medeiros Ferreira

E-mail: emily.gmf@outlook.com

ORCID: https://orcid.org/0000-0002-7081-8081 